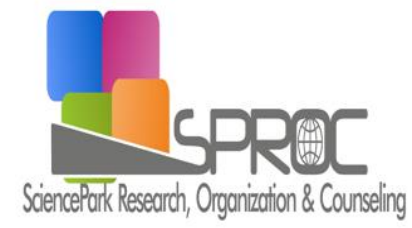

\title{
Global Journal of Sociology
}

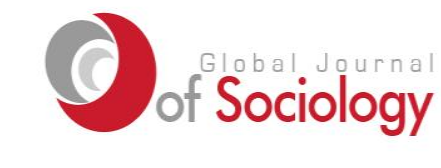

\author{
Volume 05, Issue 2, (2015)
}

\section{Message from the Editors}

\section{Dear Readers}

It is the great honor for us to publish seventh issue of Global Journal of Sociology

The journal welcomes original empirical investigations. The scope of the includes, but is not limited to; the following major topics as Child, Youth and Old Age, Communication and Art, Culture and Changes, Deviance and Social Control, Economy and Development, Education, Ethnic Relations, Human Rights and Collective Good, Gender and Human Rights, Identity, Image and Social Cohesion, Localization and Globalization, Organizations, Professions and Work, Political Sociology and Law Issues, Social Security and Public Health, Sociology of Marriage and Family, Sociology of Population and Migration, Sociology of Religion, Collective Behavior and Social Movements and Theoretical, Comparative and Historical Studies.

Post position and local autonomy have been included into this issue. The topics of the next issue will be different. You can make sure that we will be trying to serve you with our journal with a rich knowledge in which different kinds of topics are discussed in 2015 Volume.

A total of five (5) manuscripts were submitted for this issue and each paper has been rigor peer reviewed by the reviewers specialized in the related field. At the end of the review process, a total of two (2) high quality research papers were selected and accepted for publication.

We thank all the contributors who helped us to publish this issue.

Best regard

\author{
Dr. Mustafa Gündüz \\ Editor - in Chief
}

